\title{
Marketing turístico: Estudo sobre o uso da tecnologia da informação e comunicação nas agências de viagens e turismo de Balneário Camboriú (SC, Brasil)
}

\author{
Tourism marketing: A study of the use of information and \\ communication technology in travel agencies and tourism of Balneário \\ Camboriú (SC, Brazil)
}

\begin{abstract}
Marketing de turismo: Un estudio sobre el uso de la tecnología de información y la comunicación en las agencias de turismo y viajes de Balneário Camboriú (SC, Brasil)
\end{abstract}

\author{
Luiz Carlos da Silva Flores ${ }^{1}$ \\ Leila de Sena Cavalcante ${ }^{2}$ \\ Roberta Leal Raye ${ }^{3}$
}

\begin{abstract}
Resumo: As tecnologias de informação e comunicação (TIC) vêm interferindo significativamente no mercado em um cenário cada vez mais competitivo. No setor de serviços, por conta da sua intangibilidade, a qualidade da comunicação com todos os agentes ligados de forma direta às organizações faz toda a diferença para o sucesso empresarial. O setor de agenciamento no turismo vem se adaptando aos novos instrumentos de TIC. Esse estudo buscou investigar, a partir de uma pesquisa descritiva de abordagem quantitativa, o nível de utilização da tecnologia da informação e comunicação (TIC) de algumas agências de viagens e turismo da cidade de Balneário Camboriú (SC, Brasil) em seu relacionamento com clientes, fornecedores e parceiros, assim como na comercialização dos seus produtos e serviços e nas suas estratégias promocionais. Como procedimentos metodológicos, adotou-se a pesquisa bibliográfica e a pesquisa de campo, que consistiu na aplicação de questionários junto a agentes de viagens e turismo locais. Os resultados demonstraram que ferramentas como o e-mail ainda tem o mesmo nível de utilização que a telefonia fixa e móvel e as redes sociais aparecem com destaque apenas no relacionamento com os clientes. Acredita-se que uma pesquisa qualitativa com os consumidores possa contribuir para uma melhor compreensão acerca da utilização das ferramentas de TIC pelas agências de viagens e turismo.
\end{abstract}

Palavras-chave: Marketing turístico; Tecnologia de informação; Agências de viagens e turismo; Ferramentas de comunicação.

${ }^{1}$ Dr. Engenharia de Produção/UFSC. Professor/pesquisador do Programa de Mestrado em Turismo e Hotelaria Balneário Camboriú/SC e Professor do Curso de Graduação em Administração da Univali - Campus Itajaí/SC. E-mail: luiz.flores@univali.br

2 Mestranda do Programa de Mestrado Acadêmico em Turismo e Hotelaria da Univali - Campus Balneário Camboriú/SC e Professora do Instituto Federal de Educação, Ciência e Tecnologia de Roraima (IFRR) - Campus Boa Vista.E-mail: leilasena@ifrr.edu.br

3 Mestranda do Programa de Mestrado Acadêmico em Turismo e Hotelaria da Univali - Campus Balneário Camboriú/SC e Professora da Universidade do Estado de Mato Grosso (UNEMAT).E-mail: robertaraye@hotmail.com 
Abstract: The information and communication technologies (ICT) have significant effects on the market in an increasingly competitive landscape. In the services sector, because of its intangibility, the quality of communication with all stakeholders connected directly to the organizations make all the difference to your business success. The agency in tourism sector has been adapting to new ICT tools. This study aimed to investigate, from a descriptive quantitative approach, the level of use of ICT for some travel agencies and tourism city of Balneário Camboriú (SC, Brazil) in its relationship with customers, suppliers and partners, as well as in marketing their products and services and their promotional strategies. As methodological procedures adopted the literature and field research, which consisted of the application of questionnaires to travel agents and tourism sites. The results showed that tools like email still has the same level of use that the fixed and mobile telephony and social networking featured prominently only in the relationship with customers. It is believed that a qualitative research with consumers can contribute to a better understanding of the use of ICT tools by travel agents and tourism.

Keywords: Tourism marketing; Information technology; Travel agencies; Communication tools.

Resumen: Tecnología de la información y la comunicación (TIC) han interferido de manera significativa en un mercado cada vez más competitivo paisaje. En el sector servicios, debido a su intangibilidad, la calidad de la comunicación con todos los actores vinculados directamente a las organizaciones hacer toda la diferencia para el éxito de su negocio. La agencia en el sector turístico se ha ido adaptando a las nuevasherramientas de las TIC. Este estudio tuvo como objetivo investigar, desde un enfoque descriptivo cuantitativo, el nivel de uso de tecnología de la información y la comunicación (TIC) para algunas agencias de viajes y turismo de la ciudad de Balneário Camboriú (SC, Brasil) en su relación con clientes, proveedoresy socios, así como en la comercialización de sus productos y servicios y sus estrategias de promoción. Dado que los procedimientos metodológicos adoptados la literatura de investigación y de campo, que consistió en la aplicación de cuestionarios a los agentes de viajes y sitios turísticos. Los resultados mostraron que las herramientas como el correo electrónico todavía tiene el mismo nivel de uso que la telefonía fija y móvil y las redes sociales ocuparon un lugar destacado sólo en la relación con los clientes. Se cree que una investigación cualitativa con los consumidores puede contribuir a una mejor comprensión de la utilización de las TIC por las agencias de viajes y turismo.

Palabras clave: Marketing de turismo; Tecnología de la información; Agencias de viajes y turismo; Herramientas de comunicación.

\section{INTRODUÇÃO}

O turismo vem adquirindo grande espaço na economia mundial, impulsionado pelos elevados níveis de renda, pela criação de novos destinos e pelo interesse dos setores público e privado no seu desenvolvimento.

Os processos de transformação ocorridos no mundo ao longo dos anos, como a globalização, o progresso no setor de transporte, o advento da Internet, o desenvolvimento da Tecnologia da Informação e Comunicação (TIC), entre outros, sempre influenciaram a atividade turística, bem como toda a sua cadeia produtiva, na qual estão inseridas as agências de viagens e turismo, empresas privadas que foram e são, até hoje, afetadas diretamente pelas mudanças no setor provenientes principalmente das TIC, que as obrigam a repensar sua estrutura, forma de organização e operação para se manterem no mercado.

Segundo Buhalis (1998), as Tecnologias de Informação (TI) prevalecem em todas as funções de gestão estratégica e operacional e, sendo a informação elemento primordial para o turismo, as 
TI proporcionam então oportunidades e desafios para o setor. Por isso, cada vez mais as organizações e os destinos estão sendo forçados a usarem as emergentes ferramentas de TI para melhoria da sua competitividade.

Nessa perspectiva, pode-se dizer que o setor operacional (atendimento, reservas, venda de produtos e serviços) das agências de viagens e turismo foi um dos que requereu maiores alterações já que precisaram adequar-se ao novo perfil dos consumidores, agora mais exigentes, mais informados e com maior acesso às tecnologias de informação, como também às tendências atuais do mercado, primordialmente quanto aos canais de distribuição.

Os canais de distribuição, em especial a Internet, tem se tornado uma das ferramentas mais importantes para a comunicação promocional das empresas. Além disso, como bem enfatiza Middleton e Clarke (2002), "[...] a nova tecnologia pode reduzir drasticamente o custo com marketing e distribuição, trazendo aumentos significativos de $20-30 \%$ da movimentação do custo para se fazer uma venda". Por este motivo, a distribuição tem se tornado a principal questão do marketing turístico.

O município de Balneário Camboriú, destino escolhido para realização desse estudo, está localizado no Estado de Santa Catarina e faz parte da microrregião da Foz do Rio Itajaí-Açu, composta também por mais dez municípios. Sua economia gira em torno do setor terciário, tendo como uma das principais atividades o turismo. Logo, a localidade conta com um grande número de empresas ligadas ao setor, sendo as agências de viagens e turismo bastante expressivas.

Com uma população fixa de aproximadamente 108 mil habitantes (IBGE, 2011), Balneário Camboriú recebeu, durante a temporada 2009/2010 (dezembro de 2009, janeiro e fevereiro de 2010), 2 milhões de turistas, de acordo com a Secretaria de Turismo local. Essa demanda significativa que chega a aumentar o número da população flutuante em quase 200 vezes, chama a atenção de diversos segmentos ligados ao setor de turismo, como as redes de hotéis, os restaurantes, os shoppings, as agências de viagens e turismo, entre outros.

Considerando tal contexto, bem como a necessidade de adequação das empresas turísticas, em especial, das agências de viagens e turismo ao novo perfil dos turistas, é que se fez a seguinte indagação: as agências de viagens e turismo de Balneário Camboriú têm utilizado a TIC em seu relacionamento com clientes, fornecedores e parceiros e na comercialização e promoção de seus produtos e serviços?

Para responder tal questão, traçou-se como objetivo da pesquisa investigar o nível de utilização da TIC de algumas agências de viagens e turismo da cidade de Balneário Camboriú (SC, Brasil) em seu relacionamento com clientes, fornecedores e parceiros, assim como na comercialização dos seus produtos e serviços e nas suas estratégias promocionais.

Com o intuito de promover um maior entendimento, o artigo foi dividido em revisão teórica, na qual são abordadas as temáticas de marketing e sua relação com o setor de viagens e turismo, a evolução e o uso das ferramentas de tecnologias de informação e comunicação e o composto de marketing no turismo. Posteriormente, são apresentados os procedimentos metodológicos utilizados, seguidos da análise dos resultados encontrados. As considerações finais 
encerram o trabalho, expondo algumas limitações de pesquisa e sugestão para futuros pesquisadores.

\section{MARKETING E SERVIÇOS DE VIAGENS E TURISMO}

As definições de marketing sofreram muitas modificações desde a primeira utilização do termo no início do século XX. Tais conceitos passaram por fases distintas, as quais se destacam: a orientação para a produção, a ênfase em vendas, a orientação para o marketing e para a satisfação das necessidades e desejos dos clientes, a era do marketing social e do desenvolvimento sustentável e, mais recentemente, a era do marketing online, marcada pelas tecnologias digitais, principalmente rede mundial de computadores (WEB), que têm influenciado as transações entre clientes e organizações. No turismo, por exemplo, os profissionais do setor têm utilizado intensamente a WEB para fornecer informações e aceitar reservas (Morrison, 2012).

Ainda em referência à evolução do marketing, Kotler (2010) destaca que o progresso dessa área foi marcado por três fases distintas: Marketing 1.0, Marketing 2.0 e Marketing 3.0. A era do Marketing 1.0 foi impulsionada pela Revolução Industrial e teve como foco principal a venda de produtos para o mercado de massa. Já a era do Marketing 2.0 caracterizou-se pelo desenvolvimento da tecnologia da informação, tendo como objetivo satisfazer e fidelizar os consumidores, sendo estes entendidos como clientes dotados de mente e coração. E, quanto ao Marketing 3.0, esta representa a era mais recente do marketing, incentivado por uma nova onda de tecnologia e voltado para os valores, tendo o intuito de oferecer soluções para os problemas da sociedade a partir da compreensão de que mais que simples consumidores as pessoas precisam ser tratadas como seres humanos plenos, com mente, coração e espírito (Kotler, 2010).

De acordo com Middleton e Clarke (2002), embora com algumas variações, há um amplo consenso entre a maioria dos estudiosos sobre o conceito de marketing orientado a lucros e a clientes. No entanto, o mesmo autor salienta que:

A orientação a clientes nem sempre significa dar o que eles desejam, mas sim, compreender as necessidades e os desejos a fim de atendê-los de forma mais eficiente criando um sentimento empresarial para as organizações - tanto a um curto prazo de seis meses até um ano como, especialmente, a um longo prazo de vários anos. (Middleton \& Clarke, 2002, p. 24)

No que se refere ao marketing turístico, pode-se dizer que as ações mercadológicas do turismo acompanharam o seu crescimento nos últimos tempos. Contudo, estas ações estiveram sempre baseadas nas acepções do marketing tradicional - o dos bens tangíveis. Tendo em vista tal fato, muitos estudos passaram a ser ampliados no sentido de fundamentar o marketing turístico, considerando as características especiais dos serviços de viagens e turismo. Esses serviços possuem algumas peculiaridades que devem implicar numa adaptação dos princípios padrão de marketing para o setor. Dentre elas, destacam-se: a sazonalidade e outras variações no padrão da demanda; os altos custos fixos das operações dos serviços aliados à capacidade fixa em qualquer 
período de tempo e a interdependência dos produtos de turismo (Middleton \& Clarke, 2002).

Além dessas, os autores (2002) acima citados enfatizam outras características básicas e comuns a todos os serviços, das quais os serviços de viagens e turismo também não estão dissociados, como: a) inseparabilidade: ato da produção e consumo simultâneo; b) intangibilidade: capacidade que o serviço tem de não poder ser medido, tocado ou avaliado facilmente no pontode-venda antes do desempenho; c) heterogeneidade: o desempenho de serviço é exclusivo a cada cliente, ou seja, os serviços são intrinsecamente variáveis; d) qualidade de ser perecível: capacidade dos serviços ou os produtos que não forem vendidos em um determinado dia, a receita potencial que representam perde-se e não se recupera; e) inabilidade: associada à impossibilidade de se manter estoques físicos. Essas características especiais acrescidas das mencionadas anteriormente tornam os serviços de viagens e turismo particularmente diferenciados, o que exige, portanto, um gerenciamento de marketing condizente com tal diferenciação.

Corroborando com essa afirmação, Morrison (2012) declara que o marketing é um processo contínuo e sequencial, através do qual, no setor de hospitalidade e turismo, se planeja, pesquisa, implementa, controla e avalia as atividades para a satisfação tanto das necessidades e expectativas dos clientes como os objetivos das empresas, requerendo esforços de todas as organizações complementares.

\section{COMPOSTO DE MARKETING NO TURISMO}

O Composto de Marketing (Marketing Mix) é um dos conceitos essenciais da teoria do marketing descrito por Kotler e Armstrong apud Cooper (2001, p. 428) como "[...] o conjunto das ferramentas de marketing que trabalham juntas para interferir no mercado". Para Vaz (2001), o marketing mix é um ferramental importante para o gerenciamento de ações de marketing, principalmente no turismo, pois através de sua utilização correta e eficiente, é possível enfrentar todas as ameaças do meio ambiente turístico, bem como aproveitar as oportunidades que nele surgem.

A primeira concepção do composto de marketing descrita por E. J. McCarthy, contemplam os 4 P's: Produto, Preço, Promoção e Praça (Distribuição), sendo que estes quatro elementos representam as áreas fundamentais de ação mercadológica em que se assenta o sucesso de uma organização (McCarthy \& Perreault, 1997).

O produto é entendido por Kotler apud Cobra (1992, p. 335) como “[...] algo que pode ser oferecido a um mercado para criar atenção, ser adquirido, usado ou consumido, satisfazendo um desejo ou uma necessidade". No que concerne ao composto de marketing, o produto tem grande importância dentro do seu planejamento, porque "a eficácia do planejamento do marketing mix depende tanto da capacidade de selecionar o mercado-alvo correto quanto da habilidade em apresentar um produto que gere altos níveis de satisfação" (Cooper et al., 2001, p. 429). O autor atenta ainda para o fato de que as decisões relacionadas à formulação do produto envolvem a 
consideração de vários fatores importantes, tais como: o nível do serviço, os padrões de qualidade a serem adotados, a abrangência que o produto pretende ter, a marca a ser trabalhada para o seu reconhecimento no mercado e, finalmente, as características e os benefícios a serem incorporados ao produto, capazes de diferenciá-lo dos concorrentes.

Em relação ao preço, Cobra (1992, p. 468) o define como "[...] o valor justo pela posse de um bem ou de um serviço". Conforme Vaz (2001), a política de preços selecionada para um produto turístico está, muitas vezes, diretamente ligada ao desempenho de sua demanda futura. De todo o marketing mix, as decisões relativas a preços são, talvez, as mais difíceis de tomar, porque a complexidade criada pela sazonalidade da demanda e pela perecibilidade do produto deve ser considerada.

Quanto à promoção, Vaz (2001, p. 213) infere que a mesma consiste em "informar e cativar o cliente mediante os meios de comunicação". No turismo, isso significa conquistar a atenção do consumidor, sensibilizando-o para os atrativos que o produto turístico oferece. Para que a promoção ocorra de forma eficaz, é importante que se definam os objetivos de marketing que ela deve atingir. A partir dessa definição, é possível determinar as técnicas promocionais a serem utilizadas para o alcance desses objetivos.

Finalmente, a praça ou distribuição, elemento que merece maior atenção nesse estudo, refere-se aos canais de distribuição dos produtos. Para Middleton e Clarke (2002, p. 318), um canal de distribuição é "qualquer sistema organizado e servido, cujo pagamento é feito pelo orçamento de marketing e criado ou utilizado para fornecer pontos-de-venda convenientes e/ou acesso aos consumidores, fora do local de produção e consumo". Hoje, esses canais vêm sofrendo grande impacto das TIC, as quais têm permitido o contato direto entre cliente e fornecedor.

As principais funções de um canal de distribuição, enumeradas por Kotler apud Pizzinatto (2001), independentemente de seus componentes e variáveis, são: a) informação sobre os consumidores efetivos e potenciais, concorrentes e outros agentes e forças que atuam no ambiente de marketing; b) promoção sobre a oferta projetada para atrair consumidores; c) negociação; d) emissão do pedido; e) financiamento dos níveis de estoque do canal; f) aceitação de riscos, conjuntamente com a execução da tarefa do canal; g) armazenamento contínuo e movimentação de produtos até o consumo final; h) Transferência de propriedade de uma instituição de marketing para outra.

A respeito da distribuição no turismo, Cooper et al. (2001) atenta para os seguintes aspectos: não existe produto real sendo distribuído, havendo apenas pistas sendo fornecidas através de comunicação persuasiva sobre o produto; o método de venda e o ambiente no qual a aquisição do produto se dá são parte da experiência turística como um todo; e grandes quantidades de dinheiro são alocadas pela indústria para produção e impressão de material, bem como para sua entrega direta ao cliente ou ao agente de viagem varejista.

Por ser a distribuição considerada uma das variáveis mais estratégicas do composto de marketing, o planejamento dos canais de distribuição deve ser feito de forma bastante cuidadosa, principalmente no que se refere à seleção. De acordo com Vaz (2001), a seleção de canais no 
turismo deve incluir desde a representação comercial de uma operadora junto às agências de viagens e aos setores especiais, como imprensa e associações até a venda pessoal, que propicia o relacionamento mais direto do comprador com o vendedor. Além desses, vale destacar a inserção da TIC nessa seleção de canais, incluindo o uso de e-mails, e-commerce, websites, sistemas de reservas online, entre outros, pelas empresas do trade turístico, especialmente pelas agências de viagens e turismo para comunicação, divulgação e venda de seus produtos e serviços e negociações com seus fornecedores e parceiros.

Middleton e Clarke (2002) apontam os principais termos utilizados na distribuição de produtos turísticos, dos quais se enfatiza aqueles de maior importância nessa pesquisa: (a) CRSs: [...] sistemas de reservas computadorizadas para processar solicitações e reservas e manter um banco de dados dos clientes. [...]; (b) GDS: sistemas de distribuição computadorizados globais de propriedade das companhias aéreas criados nos anos 70 e 80 , antes do surgimento do software Windows e da Internet, essencialmente para fornecer acesso de e-commerce às tarifas aéreas e aos sistemas de reservas em todo o mundo para os intermediários treinados; (c) Centrais telefônicas: sistemas sofisticados de reservas e informações telefônicas de "ligação direta"[...]; (d) Website: um site criado na Internet por um negócio para fornecer informações motivadoras e, possivelmente facilidades de e-commerce para os clientes, sendo que, cada website tem um endereço exclusivo que pode ser acessado diretamente ou através de "ferramentas de pesquisa" [...]; (e) E-commerce: Comércio e varejo eletrônico na Internet, incluem transações de compra e venda on-line usando cartões de crédito e possibilitando que os clientes busquem os melhores preços e outras opções, efetuando as reservas, o pagamento e recebam confirmação.

O composto de marketing no turismo é, portanto, uma ponte que possibilita o contato entre as organizações turísticas (localidade, fornecedores, operadoras, agências de viagens, entre outras) e o meio ambiente turístico. Formulado e implementado para satisfazer o mercado-alvo, esse composto, para atuar de forma eficaz, necessita de uma compreensão completa do mercadoalvo e das necessidades de cada um dos segmentos para o qual está sendo planejado, além de uma adaptação imediata às tecnologias de informação e comunicação, as quais têm influenciado sobremaneira o mercado turístico.

\section{TECNOLOGIA DA INFORMAÇÃO E COMUNICAÇÃO E AS AGÊNCIAS DE VIAGENS E TURISMO}

O termo TIC é atribuído aos desenvolvimentos mais recentes dos hardwares, softwares e das tecnologias de comunicação, utilizadas para o processamento de aquisição, análise, armazenamento, recuperação, divulgação e aplicação da informação (Buhalis, 1998). As melhorias no processamento das TIC, na última década, têm revolucionado constantemente as suas capacidades, como as de: aumentar a velocidade de computação; diminuir tamanho do equipamento; reduzir custos de hardware e software; e melhorar a confiabilidade, compatibilidade e inter-conectividade de terminais numerosos e aplicações, tornando assim poderoso instrumental de competitividade (Buhalis, 1998). 
O progresso tecnológico e o turismo sempre andaram de mãos dadas para o futuro, considerando que desde 1980, as TIC têm mudado o turismo em nível mundial. A criação dos Sistemas Informatizados de Reserva (SIR), em 1970, e dos Sistemas de Distribuição Global (GDS), no final de 1980, seguidas pelo desenvolvimento da Internet no final de 1990, transformaram dramaticamente as melhores práticas operacionais e estratégicas na indústria do turismo (Aldebert, Dang, \& Longhi, 2010).

Assim, as TIC's também mudando radicalmente a eficiência das organizações de turismo, a gestão das empresas e a orientação para o mercado, bem como a forma dos consumidores interagirem com as organizações. Dessa forma, têm auxiliado na melhoria da qualidade do serviço e contribuído para a maior satisfação dos clientes/viajantes, permitindo que eles acessem informações confiáveis e precisas, bem como realizem reservas em uma fração de tempo e custo, sem os inconvenientes métodos convencionais (Buhalis \& Law, 2008).

As TIC's oferecem uma gama de ferramentas para facilitar e melhorar o processo de pesquisa de informação sobre o destino/produto de consumo e de pós-experiência. Logo, devido à popularidade de aplicativos de Internet, organizações de turismo como hotéis, companhias aéreas e agências de viagens têm adotado esse tipo de tecnologia da informação como parte de suas estratégias de marketing e de comunicação. A Internet, segundo Buhalis e Law (2008), tem mudado o comportamento dos viajantes, permitindo que estes se envolvam diretamente com os fornecedores e, assim, questionado o papel dos intermediários. A TIC também permitiu aos consumidores uma interação dinâmica com fornecedores e destinos e, muitas vezes, a personalização de produtos.

Diante dessa realidade, pode-se inferir que o desenvolvimento da tecnologia da informação e comunicação tem contribuído para a caracterização de uma nova fase nas agências de viagens e turismo. Os diversos canais de comunicação, como os jornais, a televisão, a Internet, entre outros, têm interferido diretamente no perfil dos turistas atuais, uma vez que, devido ao acesso mais rápido a tipos diversos de informação e facilidades, estes turistas estão se tornando cada vez mais exigentes e conscientes em relação aos produtos e serviços que desejam consumir.

O processo de mudança vivenciado pelas agências de viagens nos últimos anos foi marcado por tendências de mercado de desintermediação e reintermediação. A tendência da desintermediação significou "deixar de praticar o que já era convencional no mercado das agências de viagens e turismo [...], colocando-se como prestadora de serviços entre os provedores de transporte/hospedagem/serviços receptivos complementares e os consumidores de viagens" (Tomelin, 2001, p.85). Assim, o período de desintermediação consistiu em alterações na função tradicional das agências de viagens que deixaram de ser procuradas como distribuidoras exclusivas dos serviços de viagens.

No que se refere à tendência da reintermediação, Tomelin (2001) declara que "[...] em termos mercadológicos, as agências já estão adquirindo definições próprias para a sobrevivência e readaptação no mercado, em forma de fusão, redes, franquias ou agências virtuais, como 
processos de reintermediação". Tal tendência resultou, portanto, no mercado de agências, em um novo posicionamento comercial por parte dos agentes de viagens, transformando-os nos atuais consultores de viagens, que possuem como função auxiliar os clientes na escolha de destinos e fornecer soluções para problemas que estes venham a ter. Trata-se agora de um profissional que agrega valor ao serviço, apresentando-se como diferencial da empresa.

Em relação à diferenciação, Oliveira e Ikeda (como citado por Longhini \& Borges, 2005) asseguram que as agências de viagens, buscando diferenciação no mercado, estão incorporando diversos tipos de serviços e melhorando o padrão de atendimento de forma a alcançar ou superar a expectativa dos consumidores, e a Internet e todos os seus recursos têm sido uma das ferramentas mais utilizadas para o alcance desse objetivo.

\section{PROCEDIMENTOS METODOLÓGICOS}

A pesquisa desenvolvida nas agências de viagens e turismo de Balneário Camboriú se caracterizou como descritiva e de abordagem quantitativa. Foram adotados como procedimentos metodológicos a pesquisa bibliográfica em livros, revistas e artigos científicos sobre o assunto e a pesquisa de campo. Para a coleta de dados foram aplicados questionários eletrônicos, estruturados com questões fechadas, junto a alguns agentes de viagens e turismo da cidade. Tais questionários foram elaborados a partir de uma abordagem quantitativa, visando primordialmente à obtenção de respostas mais objetivas por parte dos entrevistados.

Balneário Camboriú possui um grande número de agências de viagens e turismo. No entanto, nem todas elas estão devidamente regularizadas. Para garantir que as agências pesquisadas nesse estudo possuíssem formalização de suas atividades, utilizou-se como critério de seleção a inserção dessas empresas no sistema de cadastro de pessoas físicas e jurídicas que atuam no setor de turismo, o CADASTUR. Executado pelo Ministério do Turismo, o CADASTUR permite o acesso a diferentes dados sobre os prestadores de serviços turísticos cadastrados, dentre eles as agências de viagens e turismo. A emissão do certificado do cadastro é feita pelo Ministério do Turismo (MTur) após análise da documentação da empresa. Isso justifica a escolha do cadastro como critério de seleção das empresas investigadas, comprovando a idoneidade das mesmas.

No CADASTUR, foram encontradas 39 agências de viagens e turismo conveniadas, mas apenas 24 questionários eletrônicos foram aplicados com os agentes dessas empresas. Isso ocorreu porque 12 agências não possuíam o e-mail cadastrado e 3 agências possuíam e-mails cadastrados incorretamente. Os questionários eletrônicos foram utilizados propositalmente como instrumento de coleta de dados, com o intuito de verificar, já num primeiro momento, o grau de familiaridade dos agentes com as ferramentas de tecnologia da informação e comunicação. Estes foram enviados para os e-mails das agências locais e estiveram disponíveis para resposta durante vinte dias, ou seja, no período de 20 de novembro a 10 de dezembro de 2011. Durante esse período, foram recebidas somente 12 respostas, as quais foram validadas, tabuladas e analisadas para a obtenção dos resultados. 
O questionário contou com uma série de 24 itens, os quais foram analisados a partir de uma escala de opinião, tipo Likert, de 5 pontos para medir o nível de utilização das ferramentas de tecnologia da informação e comunicação nas agências investigadas. Em relação à classificação dessa escala, o preenchimento do instrumento mediante à escolha dos pesos atribuídos pelos entrevistados ficou estabelecida conforme o Quadro 1.

Quadro 1. Classificação das escalas de opinião/avaliação utilizadas no questionário

\begin{tabular}{|c|c|c|}
\hline \multicolumn{2}{|c|}{ MÓDULOS/FASES DA PESQUISA } \\
\hline Pesos & Opinião & Avaliação \\
\hline 0 & Não utilizo & Não utilização \\
\hline 1 & Utilizo muito pouco & Utilização muito baixa \\
\hline 2 & Utilizo pouco & Utilização maixa \\
\hline 3 & Utilizo moderadamente & Utilização alta \\
\hline 4 & Utilizo & Utilização muito alta \\
\hline 5 & Utilizo muito & \\
\hline
\end{tabular}

Fonte: Elaboração própria (2011)

Com a porcentagem de $50 \%$ de retorno das agências de viagens e turismo pesquisadas, a quantidade de respostas obtidas foi considerada satisfatória visto que outros estudos que possuem coleta de dados mediante instrumento eletrônico obtiveram participações inferiores a desse estudo. (Mongo, Dellinghausen \& Costa, 2011).

\section{ANÁLISE DOS RESULTADOS}

A evolução na TIC vem impactando profundamente a forma como as viagens e os serviços turísticos complementares são anunciados, comercializados e distribuídos. Isso tem ocorrido porque "[...] o negócio real por trás de viagens é a informação" (Vassos, 1998).

O estudo realizado com as agências de viagens e turismo da cidade de Balneário Camboriú - SC demonstrou que a Internet é utilizada pelos agentes como ferramenta para o relacionamento dos mesmos com todos os indivíduos envolvidos diretamente à sua atividade no mercado. Das agências pesquisadas, $100 \%$ delas usam a Internet de alguma maneira em todas as relações comerciais com clientes, fornecedores e parceiros. Isso reforça a importância da Internet para o setor, bem enfatizada por Longhini e Borges (2005), quando declaram que, graças às transformações do mercado provocadas pelo aumento de vendas on-line, além das mudanças no comportamento do consumidor, a Internet está criando um ambiente competitivo completamente novo. Para as empresas que trabalham com o produto turístico, essa realidade torna-se cada vez mais esperada, já que a rede possibilita aos consumidores a oportunidade de fazer compras de acordo com a sua conveniência e no ritmo que desejarem. 
No entanto, embora se tenha notado familiaridade das agências de viagens com a principal ferramenta de TIC, no momento de seleção da amostra para esse estudo, percebeu-se que havia certa displicência, na maioria das mesmas, em relação à atualização de suas informações em alguns canais de comunicação importantes. Tal fato foi evidenciado pela inexistência ou erro de registro de e-mails de 15 das 39 agências de viagens e turismo de Balneário Camboriú cadastradas no CADASTUR - sistema de cadastro de empresas do setor turístico do Ministério do Turismo (MTur), o que impediu o acesso a elas para essa pesquisa, sendo acessadas, portanto, um total de 24 agências, como demonstrado na Tabela 1.

Tabela 1. Agências cadastradas x Agências acessadas

\begin{tabular}{l|c|c}
\hline \hline \multicolumn{1}{c|}{ Agências cadastradas no CADASTUR } & $\begin{array}{c}\text { Agências } \\
\text { cadastradas sem } \\
\text { email }\end{array}$ & $\begin{array}{c}\text { Agências cadastradas com email } \\
\text { incorreto }\end{array}$ \\
\hline \multicolumn{1}{c|}{39} & 12 & 3 \\
\hline $\begin{array}{l}\text { Total de empresas que não puderam ser } \\
\text { acessadas por email }\end{array}$ & & 15 (38,46\%) \\
\hline Total de empresas acessadas & 24 (61,54\%) \\
\hline \hline
\end{tabular}

Fonte: Dados secundários MTur

A ferramenta de e-mail (correio eletrônico) é a mais utilizada pelas organizações desde o início da popularização da Internet, tendo se transformado, por este motivo, num documento formal e legítimo de comunicação com quaisquer de seus públicos e sem custo. A despreocupação quanto à inserção do e-mail correto e à atualização de seu cadastro no MTur por parte das agências pode ser considerada, no mínimo, preocupante, uma vez que tal estudo tem como centro de discussão as TIC.

Outro fato que chamou a atenção foi o número de agências da cidade que não possuem sites próprios, estando com hospedagens apenas em sites de localização ou sem qualquer informação na rede de internet, como mostra a Tabela 2.

Tabela 2. Agências cadastradas x Agências sem informação própria na internet

\begin{tabular}{l|c|c}
\hline \hline $\begin{array}{c}\text { Agências cadastradas no } \\
\text { CADASTUR }\end{array}$ & $\begin{array}{c}\text { Agências cadastradas sem site } \\
\text { próprio }\end{array}$ & $\begin{array}{c}\text { Agências cadastradas sem site } \\
\text { próprio e não localizadas na } \\
\text { internet }\end{array}$ \\
\hline 39 & 15 & 2 \\
\hline $\begin{array}{l}\text { Total de empresas sem informação própria } \\
\text { na rede }\end{array}$ & $22(56,41 \%)$ \\
\hline \hline
\end{tabular}

Fonte: Dados secundários MTur

Contudo, a pesquisa teve acesso às respostas de apenas 12 agências de viagens e turismo, uma margem significativamente alta mediante outros trabalhos que utilizaram a mesma ferramenta de questionário on-line.

O questionário aplicado com as agências foi dividido em quatro questões básicas para 
facilitar a discussão dos resultados. Todas as perguntas referiram-se à utilização das ferramentas de TIC pelas organizações, porém a primeira questão tratava desse uso na comunicação das empresas com os clientes; a segunda, na divulgação; a terceira na comercialização de produtos e serviços e, por último, na negociação com fornecedores e parceiros.

Quando questionadas sobre o uso das ferramentas de TIC na comunicação com seus clientes, as agências de viagens tiveram um resultado satisfatório, apresentando uma utilização muito alta para recursos como e-mail, telefonia fixa e site próprio, como se nota na Tabela 3.

Tabela 3. Uso das ferramentas de TIC na comunicação com o cliente

\begin{tabular}{c|c|c|c}
\hline \hline Ferramentas de TIC & Utilização mediana & Utilização alta & Utilização muito alta \\
\hline Email & & $16,6 \%$ & $83,4 \%$ \\
\hline Site próprio & & $33,4 \%$ & $66,6 \%$ \\
\hline MSN & $66,6 \%$ & & $33,4 \%$ \\
\hline Twitter/Facebook & $66,6 \%$ & $33,4 \%$ & \\
\hline Telefonia fixa & & $16,6 \%$ & $83,4 \%$ \\
\hline \hline
\end{tabular}

Fonte: Elaboração própria - Pesquisa de campo (2011)

Percebe-se que o e-mail tem a mesma utilização da telefonia fixa, porém o primeiro possui custo zero (Hayes \& Ninemeier, 2005), oferecendo ainda uma garantia para a organização de como a informação foi passada para o cliente, podendo também agregar dados como prazos de reservas, formas de pagamento e melhor descrição sobre produtos e serviços. Essa garantia é de grande importância para as empresas, considerando um cenário em que a satisfação do consumidor tem uma relação direta com as vendas realizadas nas mesmas.

No caso da telefonia fixa, hoje, uma das principais responsáveis pelo custo fixo de uma organização, além do alto custo para seu emprego, ela oferece possibilidades de desentendimentos com o consumidor nos quesitos preços, prazos e informações dúbias.

No resultado da pesquisa, as percentagens de alta e muita alta utilização da telefonia fixa por parte das agências podem ser justificadas por diversos motivos, dentre eles: o perfil do consumidor e a necessidade de retornos imediatos. No entanto, como esse estudo se limitou a analisar os dados quantitativamente, não caberá aqui discutir questões como essas.

No que se refere ao uso da ferramenta de mensagem instantânea (MSN), observa-se que as agências obtiveram um bom resultado, já que utilizam medianamente esse recurso, que consegue tanto garantir as informações com melhor qualidade como, assim como os e-mails, atender ao imediatismo de alguns clientes. Outra vantagem que o MSN oferece para as empresas é a fidelização de clientes, já que o acesso fácil, com respostas imediatas, favorece a frequência de consultas e compras desse consumidor.

As redes sociais também aparecem com uso bastante expressivo nas respostas das organizações, o que significa um bom resultado, pois, atualmente, mais de $80 \%$ dos "internautas" brasileiros estão conectados a alguma mídia social. O volume de informação transmitida é impressionante, em média, são exibidos no YouTube cerca de 1 bilhão de vídeos por dia; 27,3 
milhões é a estimativa de postagens diárias no Twitter; e, no mundo, as pessoas despendem cerca de 5 bilhões de minutos no Facebook a cada dia (Telles, 2010).

Os sites próprios também ganham destaque nessa primeira questão. Monteiro (1999) informa sobre as vantagens que tal recurso pode oferecer para o relacionamento das empresas com o consumidor final, como consultar produtos, tarifas, disponibilidade, além de outras funcionalidades, demonstrando agilidade, eficiência e baixo custo para as mesmas.

Assim, de modo geral, pode-se dizer que os resultados dessa questão evidenciaram que as agências pesquisadas têm inserido as TIC na seleção de seus canais de comunicação com o cliente, o que, segundo Vaz (2001), constitui-se em aspecto de suma importância, já que a comunicação e a distribuição no turismo são consideradas variáveis estratégicas do composto de marketing.

Em relação ao uso das ferramentas de TIC pelas agências na sua divulgação, os resultados obtidos apresentaram certa dispersão como demonstra a Tabela 4.

Tabela 4. Uso das ferramentas de TIC na promoção da organização

\begin{tabular}{c|c|c|c|c|c}
\hline Ferramentas de TIC & $\begin{array}{c}\text { Não } \\
\text { Utilização }\end{array}$ & Utilização baixa & Utilização mediana & Utilização alta & Utilização muito alta \\
\hline Email & & & & & $100 \%$ \\
\hline Site próprio & & & & $33,4 \%$ & $66,6 \%$ \\
\hline MSN & $16,7 \%$ & $16,7 \%$ & $16,6 \%$ & $50 \%$ & $33,3 \%$ \\
\hline Sites especializados & & & $33,4 \%$ & $33,3 \%$ & $33,3 \%$ \\
\hline Twitter/Facebook & & & $33,4 \%$ & $33,3 \%$ & $50,0 \%$ \\
\hline Material impresso & & & $16,7 \%$ & $33,3 \%$ & \\
\hline \hline
\end{tabular}

Fonte: Elaboração própria - Pesquisa de campo (2011)

O uso de e-mails para a divulgação de produtos e serviços é unânime, com utilização muito alta por parte de todas as agências respondentes, o que evidencia a otimização dessa ferramenta para tal fim. Porém, alerta-se para que alguns cuidados sejam tomados para seu melhor uso. A permissão do cliente em receber em sua caixa pessoal as promoções das agências, por exemplo, é o primeiro passo para otimizar essa ferramenta. Um banco de dados atualizado, com as preferências de cada consumidor também se torna um diferencial, já que assim só serão encaminhados e-mails promocionais para aqueles clientes que tenham uma relação direta com o perfil da empresa (Mongo, Dellinghausen \& Costa, 2011).

Apesar de a pesquisa aos sites próprios ser o meio mais comum para se buscar as agências de viagens e turismo, sua utilização nas empresas investigadas representou pouco mais de $60 \%$. A importância do site como ferramenta para captação de clientes ainda não é compreendida por algumas organizações. Tal resultado é preocupante, pois, muitas vezes, por meio dos sites próprios, é que os potenciais viajantes têm acesso direto a uma riqueza muito maior de informações fornecidas pelas organizações de turismo e empresas privadas (Buhalis \& Law, 2008). De acordo com os autores, a pesquisa de informação é uma parte importante do processo de decisão de compra. Quanto mais pesquisa for realizada em uma viagem e mais informações encontradas, as necessidades do cliente serão bem atendidas. 
A partir do conteúdo comercial que apresenta em sua estrutura e das informações que disponibiliza aos clientes, o site pode se tornar um diferencial e, muitas vezes, servir como influenciador na decisão de compra dos turistas, uma vez que, segundo Buhalis e Law (2008), um consumidor bem informado é capaz de interagir melhor com os recursos locais e culturais para encontrar os produtos e serviços que atendam suas necessidades e aproveitar ofertas especiais e preços reduzidos.

O MSN na promoção das empresas aparece com alto uso em $50 \%$ das agências e uso mediano, uso baixo e não uso em $16,6 \%$ delas. As mídias sociais apresentam percentagens iguais em utilização mediana, alta e muito alta. Apesar de positivo este resultado, o cuidado no planejamento das ações ligadas a essas mídias é de extrema importância para a imagem da organização.

Os materiais impressos representam boa parte da utilização das ferramentas de comunicação para promoções. Esse recurso é muito empregado no turismo, há muitos anos, devido ao fato de as agências serem distribuidoras de produtos operacionalizados por outras empresas. De acordo com Vaz (2001), este tipo de material se constitui num conjunto de instrumentos cujo uso se situa no limite entre a ação de propaganda e de venda, pois alguns servem melhor à distribuição promocional, enquanto outras se prestam mais ao apoio de transações profissionais. Mesmo com o uso comum de imagens de 180 difundidas na internet na atualidade, as agências ainda recebem material promocional pronto dos fornecedores referentes aos produtos que comercializam, como pacotes turísticos.

$\mathrm{Na}$ terceira questão abordada com as agências de viagens, perguntou-se sobre a utilização das ferramentas para a comercialização dos seus produtos e os seguintes resultados foram obtidos, conforme Tabela 5.

Tabela 5. Uso das ferramentas de TIC na venda de produtos

\begin{tabular}{c|c|c|c|c}
\hline Ferramentas de TIC & $\begin{array}{c}\text { Não } \\
\text { Utilização }\end{array}$ & Utilização mediana & Utilização alta & $\begin{array}{c}\text { Utilização muito } \\
\text { alta }\end{array}$ \\
\hline Email & & & & $100 \%$ \\
\hline Compras on-line & & & $33,4 \%$ & $66,6 \%$ \\
\hline MSN & $16,6 \%$ & & $33,4 \%$ & $50 \%$ \\
\hline Twitter/Facebook & $66,6 \%$ & $16,6 \%$ & & $33,4 \%$ \\
\hline $\begin{array}{c}\text { Sistema GDS } \\
\text { Telefonia fixa ou } \\
\text { celular }\end{array}$ & & & $33,4 \%$ & $63,4 \%$ \\
\hline \hline
\end{tabular}

Fonte: Elaboração própria - Pesquisa de campo (2011)

O resultado mostra que o e-mail é usado por $100 \%$ das agências para a venda de seus produtos. Outra ferramenta bastante utilizada pelas organizações é o sistema GDS que, como explica Middleton e Clarke (2002), é o sistema que fornece acesso de e-commerce just time às tarifas aéreas e aos sistemas de reservas em todo o mundo. Apesar de ter surgido no segmento das empresas aéreas, hoje, são usados por fornecedores de todos os segmentos ligados direta e 
indiretamente à atividade, como locadoras de veículos, empresas de seguros, hotéis, entre outros. O custo do sistema GDS pode variar de acordo com o segmento e o número de emissões mensais, podendo chegar a custo zero.

As compras online e o MSN aparecem com 33,4\% de alta utilização pelas agências, no entanto, uma porcentagem de $16,6 \%$ delas não utiliza o MSN para a venda de produtos. 0 commerce, que se trata de compras e vendas on-line, usando cartões de crédito, vem crescendo muito desde a década de 80 , tendo nos últimos anos atingido seu ápice de uso, já que também possibilita ao consumidor a busca por melhores produtos e preços.

Para Buhalis (1998), a utilização das TIC para comercialização de produtos e serviços não só habilita os consumidores a identificar, personalizar e comprar produtos de turismo, como também apóia a globalização da indústria, fornecendo ferramentas eficazes aos fornecedores para desenvolver, gerenciar e distribuir as suas ofertas em todo o mundo.

Apesar de tal evidência, a pesquisa mostra que nas agências investigadas a telefonia fixa e a telefonia móvel (celular) continuam entre as ferramentas de preferência dos agentes. Nesse caso, não se sabe se por preferência do consumidor ou da organização, uma vez que é a ferramenta de mais alto custo para a empresa. Porém, cabe ressaltar que, segundo Wolfe, Hsu e Kang apud Buhalis e Law (2008), as razões que impedem os consumidores de comprarem produtos de viagens on-line são a falta de serviço de pessoal, as questões de segurança, a sua falta de experiência nesse tipo de compra e a demora.

Em relação às mídias sociais, os resultados variaram entre $33,4 \%$ (uso muito alto) e $66,6 \%$ (não uso). Para Mongo, Dellinghausen e Costa (2011), as mídias sociais têm como objetivo principal reforçar relacionamentos, ação fundamental na gestão de marketing de diversas empresas de diferentes segmentos econômicos no mundo.

Quando questionadas sobre a utilização de ferramentas de TIC na comunicação e na negociação com fornecedores e parceiros, as respostas das agências foram similares, como mostra a Tabela 6.

Tabela 6. Uso das ferramentas de TIC na negociação com fornecedores e parceiros

\begin{tabular}{c|c|c|c|c|c}
\hline Ferramentas de TIC & $\begin{array}{c}\text { Não } \\
\text { Utilização }\end{array}$ & $\begin{array}{c}\text { Utilização } \\
\text { baixa }\end{array}$ & $\begin{array}{c}\text { Utilização } \\
\text { mediana }\end{array}$ & Utilização alta & $\begin{array}{c}\text { Utilização } \\
\text { muito alta }\end{array}$ \\
\hline Email & & & & & $100 \%$ \\
\hline Compra on-line & & & & $33,4 \%$ & $66,6 \%$ \\
\hline MSN & $16,6 \%$ & $50 \%$ & & & $100 \%$ \\
\hline Twitter/Facebook & & & & & $33,4 \%$ \\
\hline $\begin{array}{c}\text { Sistema GDS } \\
\text { Telefonia fixa ou } \\
\text { celular }\end{array}$ & & & & $100 \%$ \\
\hline \hline
\end{tabular}

Fonte: Elaboração própria - Pesquisa de campo (2011)

A pesquisa comprovou que $100 \%$ das agências utilizam o e-mail, o MSN e a telefonia fixa ou móvel (celular) na comunicação e negociação com fornecedores e parceiros. As compras online 
e o sistema GDS surgem com maiores percentuais de alta utilização. Pode-se deduzir que essa seja uma resposta ao perfil das empresas produtoras de turismo como as operadoras nacionais, que seguem o mesmo caminho das companhias aéreas na comercialização pela Internet de todos os seus serviços.

As mídias sociais ainda aparecem tímidas nos resultados, com utilização alta por apenas uma pequena parcela das organizações $(33,4 \%)$, contra a utilização baixa de $50 \%$ e não utilização de $16,6 \%$. Essa realidade é justificável, já que, apesar de $80 \%$ dos internautas brasileiros estarem conectados em alguma rede social, o uso em massa da mesma se restringe ainda à utilização doméstica.

\section{CONSIDERAÇÕES FINAIS}

O turismo por ser essencialmente uma atividade econômica vem sofrendo interferência direta das TIC. A partir dos anos 80 , essa interferência foi otimizada pela criação do sistema GDS, que passava a reservar e a comercializar as passagens aéreas em todo mundo por um sistema online a just time.

Estima-se que hoje quase um quarto da população mundial possua acesso à Internet. No Brasil, esse número aumentou de 27\% em 2007 para 48\% em 2011 (EPOCA, 2011). Nesse cenário, a comercialização de produtos e serviços vem crescendo significativamente e, no segmento de turismo, essa realidade não é diferente.

Essa pesquisa buscou investigar, dentro desse contexto, investigar o nível de utilização da TIC de algumas agências de viagens e turismo da cidade de Balneário Camboriú (SC, Brasil), com registro no CADASTUR, em seu relacionamento com clientes, fornecedores e parceiros, assim como na comercialização dos seus produtos e serviços e nas suas estratégias promocionais.

No momento de seleção das empresas, já se percebeu um dado relevante ao estudo: mais de um terço das agências inseridas no sistema CADASTUR não possuíam e-mail cadastrado ou se o tinham estava registrado incorretamente. Sendo o e-mail a principal ferramenta de TIC usada pelas organizações, podendo-se considerar tal fato, no mínimo, uma falta de atenção grave à importância dessa ferramenta de acesso e distribuição de informações.

$O$ inexpressivo número de agências que possuem site próprio também chamou atenção nos resultados. Considerando o baixo custo de aquisição dessa ferramenta, bem como sua grande utilização pelo consumidor atual que, com as novas possibilidades de busca na rede, acabam tendo o website como uma das principais referências na pesquisa por preços e serviços, isso não deveria ocorrer. Além disso, sabe-se que o site facilita a comunicação direta com o cliente final, possibilitando a divulgação de informações que promovam a organização e reforcem a sua credibilidade diante da apresentação prévia de sua estrutura e organização.

O uso do e-mail foi outro aspecto que se destacou nos resultados da pesquisa. Mesmo sendo uma ferramenta sem custo e de reconhecimento legítimo, a sua utilização pelas empresas investigadas é igual ao da telefonia fixa e móvel, esta considerada o custo fixo mais alto de uma 
organização. Esse resultado foi comum a praticamente todas as agências respondentes. Acreditase que, nessa questão, uma análise qualitativa poderia esclarecer melhor se esse fato ocorre por falta de familiarização da empresa com a ferramenta de e-mail ou se a mesma o faz para atender o perfil do seu consumidor.

As mídias sociais apresentaram um significativo nível de utilização por parte das agências, principalmente no relacionamento com os clientes, ainda aparecendo timidamente na promoção de seus produtos e serviços. Essa ferramenta tem ganhado cada vez mais a preferência dos internautas no país. A estimativa é que $80 \%$ deles façam parte de alguma rede social. Para isso, é importante que a empresa saiba utilizar seu perfil para fortalecer essa relação com informações de interesse relevante a fim de não conquistar a antipatia dos seus "amigos" ou "seguidores".

A pesquisa teve como limitação a discussão de informações que precisariam de uma abordagem quanti-qualitativa. Como sugestão para futuros pesquisadores que se interessem pelo tema, sugere-se um estudo de abordagem qualitativa, o qual investigue os consumidores das agências de viagens e turismo, com o intuito de compreender se a escolha das ferramentas se dá apenas por decisão da organização ou se os mesmos têm influenciado ou não no avanço da utilização de algumas ferramentas de TIC.

Enfim, percebeu-se que as agências de viagens e turismo de Balneário Camboriú (SC) ainda utilizam as ferramentas de TIC aquém do seu potencial de comunicação com seus clientes, fornecedores e parceiros. A promoção de seus produtos segue padrões tradicionais como a produção de material impresso, sendo apenas o e-mail a ferramenta de TIC mais utilizada por elas.

\section{REFERÊNCIAS}

Aldebert, B., Dang, R.J., \& Longhi, C. (2010). Innovation in the tourism industry: the case of tourism@. Tourism Management. Recuperado de http//www.elsevier.com/locate/tourman.

Buhalis, D. (1998). Strategic use of information tecnologies in the tourism industry. Tourism Management, 19(5), p. 409-421.

Buhalis, D., \& Law, R. (2008). Progress information technology and tourism management: 20 years on and 10 years after the Internet - the state of tourism research. Tourism Management, 609-623. Recuperado de http//www.elsevier.com/locate/tourman.

CADASTUR. Sistema de cadastro de pessoas físicos e jurídicos que atuam no setor de turismo. Recuperado de http://www.cadastur.turismo.gov.br/cadastur/index.action.

Cobra, M. (1992). Administração de Marketing. São Paulo: Atlas.

Cooper, C. et al. (2001). Turismo: princípios e prática. Porto Alegre: Bookman.

ÉPOCA. (2011). Metade da População Brasileira tem acesso à internet. Recuperado de http://revistaepoca.globo.com/Ciencia-e-tecnologia/noticia/2011/11/metade-da-populacao-brasileira-temacesso-internet.html.

Hayes, D. K., \& Ninemeier, J. D. (2005). Gestão de operações hoteleiras. São Paulo: Pearson Prentice Hall.

IBGE. Recuperado de www.ibge.gov.br. 
Kotler, P. (2010). Marketing 3.0. Rio de Janeiro: Elsevier.

Longhini, F. O., \& Borges, M. P. (2005). A influência da internet no mercado turístico: um estudo de caso nas agências de viagens de Piracicaba (SP) e região. Caderno Virtual de Turismo, 5(3).

McCarthy, E. J., \& Perreault, W. D. Marketing Essencial: Uma abordagem gerencial e global. São Paulo: Atlas, 1997.

Middleton, V. T. C., \& Clarke, J. (2002). Marketing de Turismo: Teoria e Prática. Rio de Janeiro: Elsevier.

Mongo, T. S., Dellinghausen, C. N., \& Costa, J.I. Marketing Digital: uma análise da hotelaria catarinense sob a ótica de seus gestores. Recuperado de http://www.eumed.net/rev/turydes/10/mdc-resum.htm:eumed.

Monteiro, P. (1999). Automação 5 estrelas: sistemas de administração hoteleira invadem o mercado, facilitam a troca interna de informações e tornam o atendimento mais ágil e eficaz. Automação, 30-33.

Morrison, A. (2012). Marketing de Hospitalidade e Turismo. Cengage Learning.

Pizzinatto, N. K. (2001). Variáveis de adequação de canais de distribuição a produtos. Revista IMES, São Paulo.

SECTURBC. Recuperado de http://www.secturbc.com.br/pt index.php?s=estatisticas.

Telles, A. (2010). A revolução das mídias sociais: cases, conceitos, dicas e ferramentas. São Paulo: M. Books do Brasil.

Tomelin, C. A. (2001). Mercado de agências de viagens e turismo: como competir diante das novas tecnologias. São Paulo: Aleph.

Vassos, T. (1998). Marketing estratégico na Internet. São Paulo: Makron Books.

Vaz, G. N. (2001). Marketing turístico: receptivo e emissivo. São Paulo: Pioneira.

Artigo recebido em: 26/04/2012.

Artigo aprovado em: 01/11/2012. 